\title{
DOENÇA PELO CORONAVÍRUS 2019: UMA REVISÃ̃ SISTEMÁTICA
}

Coronavirus disease 2019: A sistematic review

Enfermedad por coronavirus 2019: Una revisión sistemática

Victor Nepomuceno Morais*1, Fernanda Carvalho Barros Dias ${ }^{1}$, Tayná Borges Aguiar Santana ${ }^{1}$, Lucas Guimarães Maciel ${ }^{1}$, Yasmin Cabral de Souza ${ }^{1}$, Alexandre Andrade Mescoloti ${ }^{1}$, Flávio Augusto de Pádua Milagres $^{2}$, Raphael Sanzio Pimenta ${ }^{3}$

${ }^{1}$ Curso de Medicina, Universidade Federal do Tocantins, Palmas-TO, Brasil.

${ }^{2}$ Instituto de Ciências Biológicas, Universidade Federal do Tocantins, Palmas-TO, Brasil.

${ }^{3}$ Laboratório de Microbiologia Ambiental e Biotecnologia (LAMBIO), Universidade Federal do Tocantins, PalmasTO, Brasil.

*Correspondência: Laboratório de Ciências, Instituto de Ensino Superior, Av. NS 15, 109 Norte, Palmas, Tocantins, Brasil.CEP:77.010-090.e-mail victor.nepomuceno@mail.uft.edu.br.

\section{RESUMO}

O SARS-CoV-2, que causa a patologia conhecida como COVID-19, foi identificado em dezembro de 2019 como a causa de uma série de casos de pneumonia na cidade chinesa de Wuhan. O número de casos aumentou consideravelmente nos meses subsequentes e a Organização Mundial da Saúde (OMS) declarou no dia 11 de março de 2020 a pandemia de COVID-19. Trata-se de um vírus de RNA, envelopado e que possui uma alta taxa de transmissão. A apresentação clínica pode variar de um quadro assintomático ou leve, até casos graves que cursam com insuficiência respiratória. Febre, tosse, dispneia, fadiga, mialgia generalizada e cefaleia são os sintomas comumente observados. Até a data de realização desse estudo, não haviam terapias específicas que tenham apresentado eficácia claramente comprovada. O objetivo desse artigo foi abordar diversos aspectos sobre o SARSCoV-2, incluindo a epidemiologia, quadro clínico, diagnóstico e tratamento da COVID-19. Realizou-se uma revisão sistemática da literatura, com o uso da base de dados do Pubmed e relatórios do Ministério da Saúde do Brasil e da OMS, que resultou na seleção de 77 referências baseadas no Preferred Reporting Items for Systematic Reviews and Meta-Analyses (PRISMA).

Palavras-chave: "covid-19", "2019-nCoV" e "SARS-CoV-2"

\section{ABSTRACT}

The SARS-CoV-2, which causes the pathology known as COVID-19, was identified in December 2019 as the cause of a series of pneumonia cases in the chinese city of Wuhan. The number of cases increased considerably in the subsequent months and the World Health Organization (WHO) declared on March 11 ${ }^{\text {th }}, 2020$ the COVID-19 pandemic. It is an enveloped RNA virus and that has a high rate of transmission. The clinical presentation varies from asymptomatic or mild, to severe cases with respiratory failure. Fever, cough, dyspnea, fatigue, generalized myalgia and headache are the most common symptoms observed. Until the date of this study, there weren't specific therapies with a proven efficacy. The objective of this study was to address some aspects of the SARS-CoV-2, including the epidemiology, clinical features, diagnosis and treatment of COVID-19. A systematic review was conducted with the use of Pubmed's data base and reports of the WHO and the Brazilian Ministry of Health, which resulted in the selection of 77 references based on the guidelines of Preferred Reporting Items for Systematic Reviews and Meta-Analyses (PRISMA).

Keywords: "covid-19", "2019-nCoV” e "SARS-CoV-2" 


\section{RESUMEN}

El SARS-CoV-2, que causa la patologia conocida como COVID-19, fue indentificado en diciembre de 2019 como la causa de una serie de casos de neumonia en la ciudad chinesa de Wuhan. El numero de casos aumentou considerablemente y en los meses siguientes la organización mundial de la salud (OMS) declaro en el dia 11 de marzo del 2020 la pandemia de COVID-19. Se trata de un vírus de RNA, envuelto y que tiene un alto nível de transmisión. La presentecion clinica puede variar de um cuadro asintomatico o ligero, hasta casos graves con insuficiencia respiratória. Fiebre, tos, disneia, cansancio, dolor muscular generalizada y cefalea son los sintomas mas comunes observados.hasta la fecha de realizacion de este estudio no havian terapias especificas que tenga presentado eficácia comprovada. El objetivo de este articulo fue abordar aspectos sobre SARS-COV-2, incluyendo la epidemiologia, cuadro clinico, diagnostico y tratamiento de la covid-19. Se realizou una revision sistemática de la literatura, con el uso de la base de datos de Pubmed y los reportes del ministério de la salud de Brazil y de la OMS, que resulto en la selecion de 77 referencia basadas en la Preferred Reporting Items for Systematic Reviews and Meta-Analyses (PRISMA).

Descriptores: "covid-19", "2019-nCoV" e "SARS-CoV-2".

\section{INTRODUÇÃO}

O surto de SARS-CoV-2, vírus que causa a doença denominada COVID-19, foi declarado uma emergência de saúde pública de importância internacional pela Organização Mundial da Saúde (OMS) no dia 30 de janeiro de 2020. Posteriormente, no dia 11 de março de 2020, a OMS declarou a pandemia de COVID-19 (Kim et al., 2020). O SARS$\mathrm{CoV}-2$ é um vírus de RNA envelopado, com alta virulência e com escassas informações, devido ao seu recente surgimento. A COVID-19 possui como sintomas comuns febre, tosse, dor de garganta, dor de cabeça, fadiga, mialgia e dispneia, o que a torna semelhante a outras síndromes respiratórias. Em pacientes idosos e com comorbidades foi notório uma maior mortalidade, comparados com pacientes adultos e saudáveis (Singhal, 2020).

Os primeiros casos de infecção por SARSCoV-2 ocorreram em dezembro de 2019 na cidade chinesa de Wuhan, contexto no qual a suspeita surgiu após o aparecimento de uma série de casos de pneumonia sem causa aparente. Atualmente tem acometimento global, com vários países em estágio crítico. Além dele, outros dois coronavírus ficaram conhecidos nos últimos 20 anos pelo potencial de causar síndrome respiratória grave: o vírus denominado SARS-CoV, o qual causa a Síndrome Respiratória Aguda Grave e que teve os primeiros casos relatados em 2002 na China, e o MERS-CoV, o qual provoca a Síndrome Respiratória do Oriente Médio e surgiu na Arábia Saudita em 2012 (Ryu e Chun, 2020; Stoecklin et al., 2020; Singhal et al., 2020).

O diagnóstico da COVID-19 tem sido feito a partir de um exame molecular específico utilizando-se amostras respiratórias, que consiste no esfregaço nasofaríngeo, aspirado endotraqueal, lavado bronco alveolar, entre outros. O exame é realizado em casos suspeitos e que representam gravidade, como os pacientes que possuem febre, tosse seca e dispneia (Zhang et al., 2020).

O tratamento específico da COVID-19 ainda se encontra muito incerto. Estudos estão sendo feitos sobre a associação de antivirais à melhora da doença, porém ainda não muito conclusivos. Estes incluem a ribavirina, lopinavir-ritonavir, hidroxicloroquina, entre outros. Um aspecto importante no manejo é o suporte sintomático e acompanhamento clínico do paciente, sendo também necessário garantir medidas de prevenção como o isolamento do indivíduo infectado e higienização adequada. (Jin et al., 2020). 


\section{MATERIAIS E MÉTODOS}

Trata-se de uma revisão sistemática da literatura cujo levantamento bibliográfico foi feito por meio da base de dados PubMed utilizando-se os descritores "covid-19", "2019-nCoV” e "SARS-CoV2". A escolha destas palavras-chave justifica-se por estarem relacionadas ao objeto de estudo e por pertenceram ao catálogo de descritores do PubMed (MeSH terms). A combinação foi realizada com a utilização do operador booleano "or". O processo de busca, neste primeiro momento, permitiu a identificação de 466 documentos.

Foram selecionados por meio de filtros de busca os estudos observacionais, multicêntricos, comparativos, revisões da literatura, guidelines e relatos de casos publicados no período entre 31 de dezembro de 2019 a 08 de abril de 2020, na língua inglesa, disponíveis com texto completo e que tratavam da infecção do novo coronavírus (SARSCoV-2) em humanos, obtendo-se 83 artigos.

Posteriormente, por meio da leitura dos títulos e resumos, foram excluídos os estudos que não faziam referência à temática abordada (SARS-Cov-2, epidemiologia, quadro clínico, diagnóstico e tratamento da COVID-19). Após avaliação dos títulos e resumos, restaram 74 trabalhos, destes, 4 artigos eram indisponíveis na versão online, sendo excluídos da revisão.

Além dos artigos supracitados, também foram referenciados o $6^{\circ}$ boletim epidemiológico especial do Centro de Operações de Emergências em Saúde Pública da COVID-19, o Painel de casos de doença pelo Coronavírus 2019 (COVID-19) no Brasil, o Guia de Vigilância Epidemiológica e o Protocolo de Manejo Clínico do Coronavírus (COVID-19) na Atenção Primária à Saúde do Ministério da Saúde; as Orientações Provisórias da Vigilância Mundial da COVID-19 e o $75^{\circ}$ relatório de situação da OMS e as Projeções e Estimativas da população do Brasil e das Unidades da Federação do Instituto Brasileiro de Geografia e Estatística (IBGE).

A descrição dessa revisão sistemática foi 3 baseada nas diretrizes do Preferred Reporting Items for Systematic Reviews and Meta-Analyses (PRISMA).

Figura 1. Busca e seleção de artigos de acordo com o PRISMA.

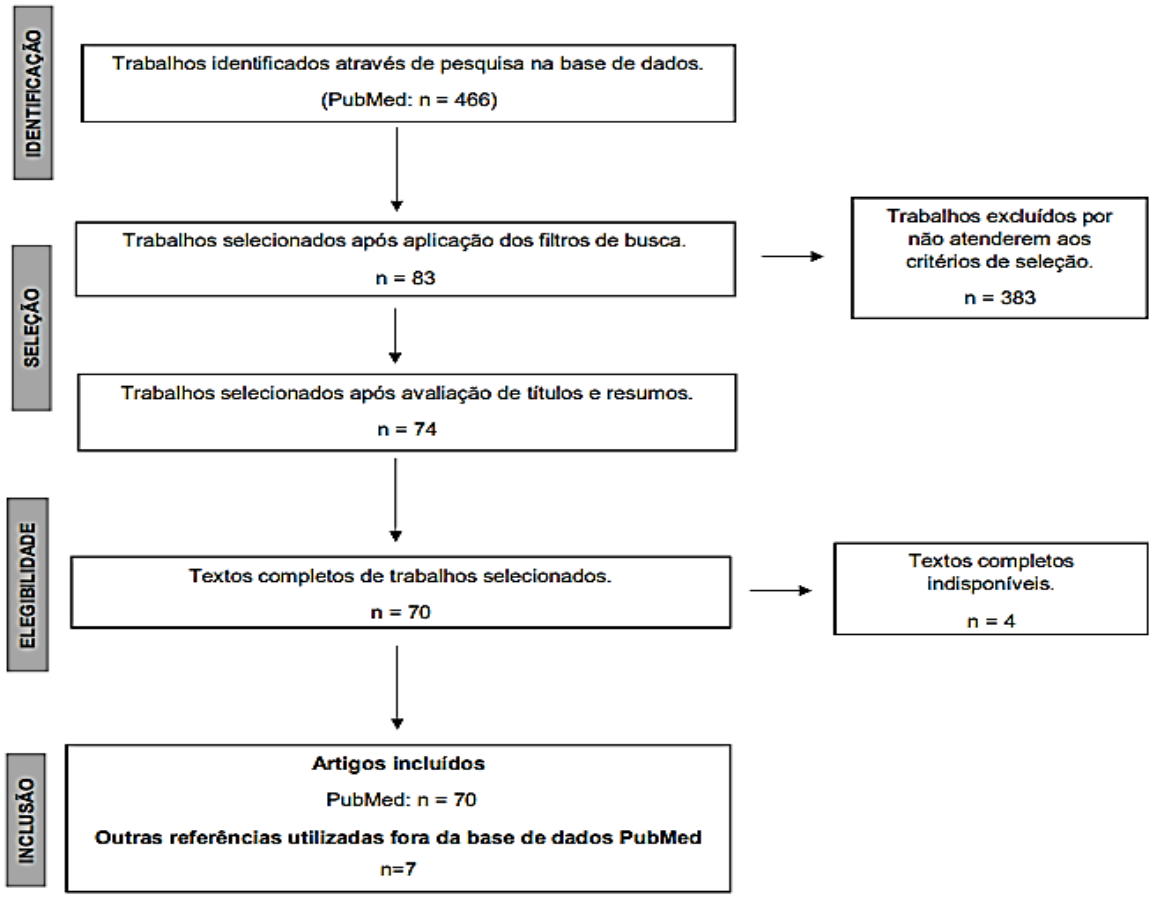




\section{RESULTADOS E DISCUSSÃO}

\section{SARS-Cov-2}

Os primeiros casos relatados da COVID-19 foram na China, na primeira quinzena de dezembro de 2020. Eram pacientes com quadro de pneumonia viral inicialmente não identificada, alguns com gravidade acentuada, e que tiveram recente histórico de contato com animais selvagens em um mercado na província de Wuhan. Inicialmente foi nomeado como 2019nCoV (2019-novel coronavirus) pela OMS e, posteriormente, designado como SARS-CoV-2 (Coronavírus da Síndrome Respiratória Aguda Grave 2). Em abril de 2020, a doença atingiu a marca de 1 milhão de casos confirmados no mundo (Sun et al., 2020; Cheng e Shan, 2020; Zhang, 2020).

O SARS-CoV-2 é um vírus de RNA, envelopado, cujo genoma varia entre 26 e $32 \mathrm{kbs}$. Possui um nucleocapsídeo composto por RNA e proteína fosforilada, protegido externamente por uma membrana de bicamada fosfolipídica, glicoproteínas triméricas e, em alguns vírus dessa família, a proteína hemaglutinina esterase. Sua morfologia na microscopia eletrônica é similar a uma coroa, por isso o nome coronavírus (Li e Fan et al., 2020; Park et al., 2019).

A família coronaviridae é dividida genotipicamente nos gêneros $\alpha, \beta$, y e $\delta$, sendo que os $\beta$-coronavírus possuem 4 linhagens, de A a D. Os diferentes Coronavírus (CoVs) possuem diversos hospedeiros e tropismos teciduais. Há cerca de 30 CoVs conhecidos que infectam mamíferos, aves e outros animais (FUNG et al., 2020; LI et al., 2020; PARK et al., 2019). Os humanos são infectados por $\alpha$ e $\beta$-coronavírus e, até 2019, eram conhecidos 6 destes vírus - HCoV-229E, HCoV-OC43, HCoV-NL63, HKU1, MERS-CoV e SARS-CoV (Li e Fan et al., 2020; Chen et al., 2020; Ye et al., 2020). Os vírus HCoV-229E, HCoV-OC43, HCoV-NL63 e HKU1 estavam associados à infecção leve do trato respiratório superior, enquanto MERS-CoV e SARS$\mathrm{CoV}\left(\begin{array}{l}1 \\ \text { e }\end{array}\right)$ causam doença do trato inferior com possível síndrome respiratória aguda grave (Li e Fan et al., 2020; Chen, Liu e Guo, 2020; Ye et al., 2020; Adhikari et al., 2020).

Desde o surgimento dos primeiros casos em Wuhan, a origem animal do SARS-CoV-2 tem sido estudada. A literatura mostra que há $96 \%$ de semelhança entre o genoma deste vírus com o do $\mathrm{CoV}$ RaTG13, que foi isolado em morcegos, e que o inicialmente chamado 2019 - nCoV seria muito próximo do já conhecido SARS-CoV, com cerca de $70 \%$ de similaridade (Wu et al., 2020; Cheng e Shan, 2020; Ye et al., 2020; Adhikari et al., 2020; Peng et al., 2020). Mais recentemente, a origem do SARS-CoV-2 tem sido associada a um mamífero em vias de extinção, o pangolim (Manis javanica), que também é 4 infectado por um $\beta$-coronavírus cujo genoma possui homologia entre $85-92 \%$ em relação à sequência nucleotídica do vírus humano (Ye et al., 2020).

Os CoVs são parasitas de vários animais, domésticos e selvagens, como já foi dito e, geralmente, aqueles de origem animal não são transmitidos aos seres humanos, exceto os SARS e MERS. Estes se espalham entre os humanos através do contato próximo entre as pessoas infectadas, através de gotículas originadas de espirro ou tosse ou por aerossol (Adhikari et al., 2020; Lake, 2020). A transmissão também pode ocorrer por meio do contato com objetos contaminados, nos quais o SARS-CoV-2 pode permanecer entre 2 horas a 9 dias, a depender do tipo de material, temperatura local e outros fatores (Adhikari et al., 2020; Kampf, et al., 2020). A transmissibilidade desse novo coronavírus é estimada pela OMS em 1.4-2.5 (número médio de pessoas que podem ser contaminadas por um indivíduo doente), comparativamente maior que de outras doenças 
infecciosas como a gripe sazonal, caxumba e outras (Lake, 2020).

A incubação média do SARS-CoV-2 é variável na literatura, com um período total de 1 a 14 dias, na maioria dos casos 3 a 7 dias. Durante esse período, os pacientes são transmissores da COVID-19 (Jin et al., 2020; Zheng, 2020; Ye et al., 2020; Adhikari et al., 2020; Lake, 2020; Guo et al., 2020; XU et al., 2020; Liu et al., 2020a; Meo et al., 2020; Rothe et al, 2020). Esse período é maior que do SARS-CoV, cuja incubação média é de 1 a 4 dias, no máximo até 11 dias, enquanto no caso do MERS-CoV pode durar de 2 a 13 dias (Ye et al., 2020; Xu et al., 2020).

Assim como o SARS-CoV, o novo coronavírus usa o receptor ACE2 (Human angiotensin converting enzyme) encontrado nos pneumócitos tipo II para entrada nas células através da ligação desse receptor com suas glicoproteínas de superfície (Singhal, 2020; Ye et al., 2020; Guo et al., 2020; Giwa et al., 2020; Sun et al., 2020). Após a entrada na célula, o vírus consegue suprimir a resposta de Interferongama, induz a aproximação e ativação de células inflamatórias (neutrófilos e macrófagos) gerando inflamação do tecido pulmonar. Ocorre neste processo a resposta imune TH2/TH17 para produção de anticorpos contra o vírus (Singhal, 2020; Sarzi-Puttini et al., 2020). Este vírus gera desregulação da produção e secreção de citocinas inflamatórias, que ficam bastante aumentadas, algo observado sobretudo nos pacientes com maior gravidade (Sarzi-Puttini et al., 2020). Essa exacerbação da atividade do sistema imune pode gerar danos em outros órgãos, disfunção orgânica e morte (Sarzi-Puttini et al., 2020; Yi et al., 2020).

\section{Epidemiologia}

Como se sabe, a pandemia da COVID-19 teve início em dezembro de 2019 na cidade de Wuhan, província de Hubei, China. Até o dia 4 de abril de
2020, segundo dados fornecidos pelo $75^{\circ}$ relatório de situação da Organização Mundial de Saúde, havia 1.051.697 casos confirmados globalmente, com 56.986 mortes, com uma taxa de letalidade de $5,41 \%$ e tendo suas maiores incidências nos continentes Europa, Américas e Pacífico Ocidental, concentrando 92,52\% dos casos e 92,90\% dos óbitos. As maiores letalidades estavam presentes em países africanos (World Health Organization, 2020a).

Figura 2. Cinco primeiros países com os maiores números de casos confirmados ao redor do mundo.

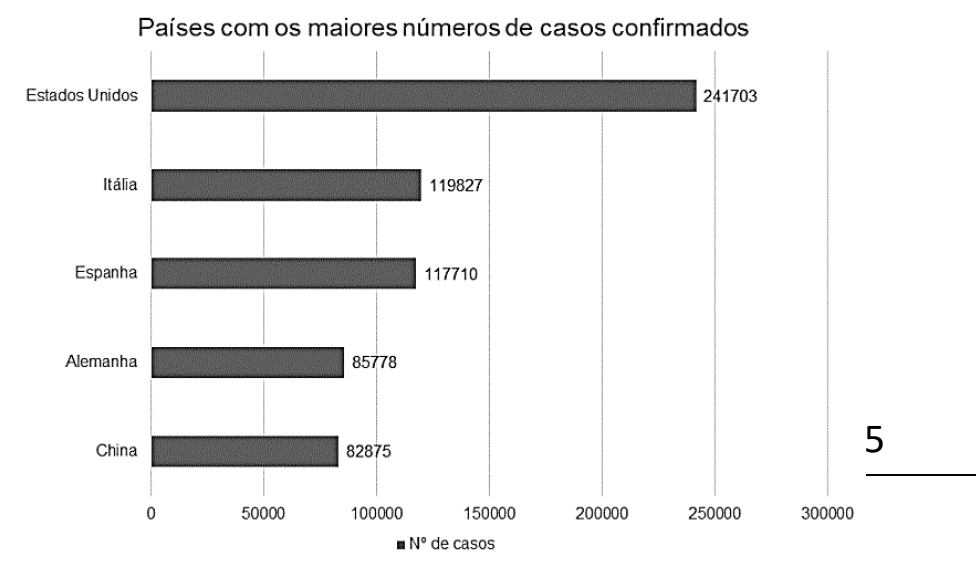

Fonte: Organização Mundial da Saúde. Dados atualizados em 04 de abril de 2020, às 05h, sujeitos a revisões.

Figura 3. Cinco primeiros países com as maiores taxas de letalidade de COVID-19.

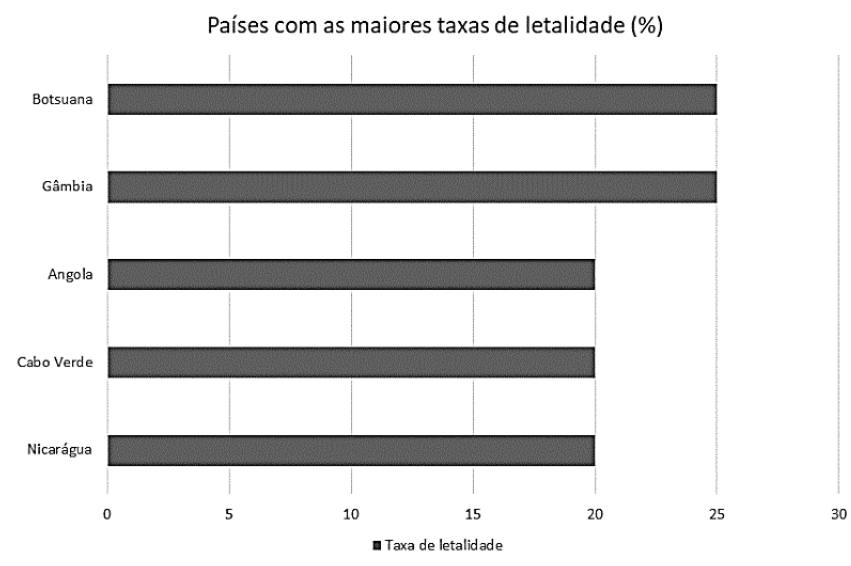

Fonte: Organização Mundial da Saúde. Dados atualizados em 04 de abril de 2020, às 05 h, sujeitos a revisões.

No contexto brasileiro, até o dia 4 de abril de 2020, de acordo com dados do Ministério da Saúde, havia 10.278 casos, com 432 mortes, representando 
uma taxa de letalidade de 4,20\%. A maioria dos casos se concentrava nas regiões nordeste (1642 casos), sul (1139 casos) e sudeste (6295 casos), representando $88,30 \%$ do total. O coeficiente de incidência por 100.000 habitantes foi calculado considerando a projeção do Instituto Brasileiro de Geografia e Estatística para o ano de 2020, que, para o Brasil, estava estimado em 4,86/100.000 (IBGE, 2020). O Distrito Federal possuía a maior incidência até essa data, 14,91/100.000 (Ministério da Saúde, 2020a).

Figura 4. Coeficiente de incidência de COVID-19 considerando a projeção do IBGE para 2020 por UF.

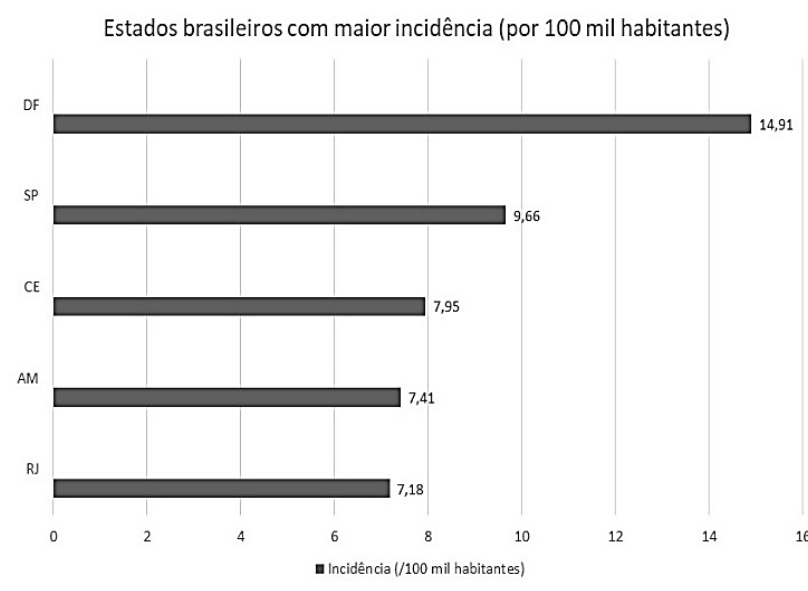

Fonte: Ministério da Saúde. Dados atualizados em 04 de abril de 2020, sujeitos a revisões.

Figura 5. Distribuição por UF dos casos de COVID-19 no Brasil.
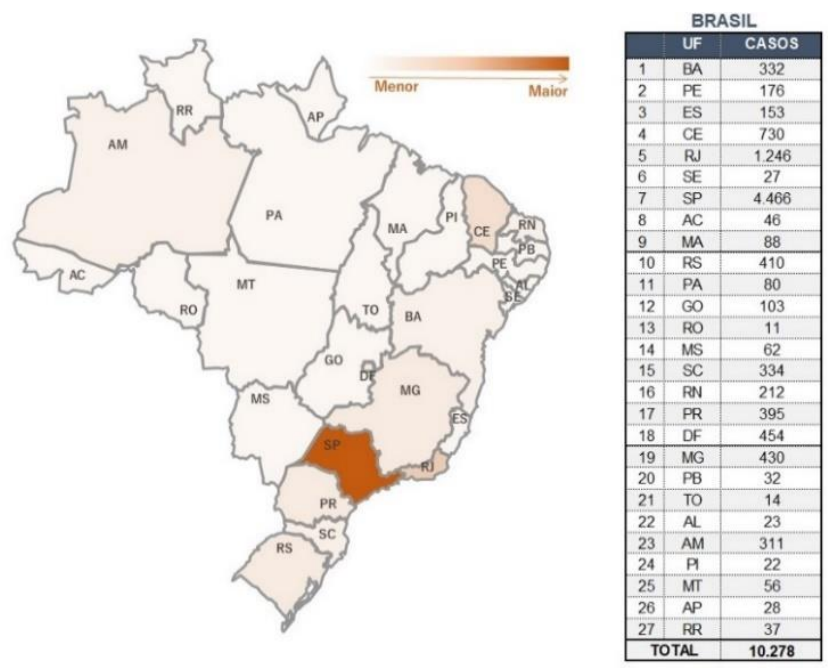

Fonte: Ministério da Saúde. Dados atualizados em 04 de abril de 2020, sujeitos a revisões.
Ultimamente, referente à distribuição de óbitos no Brasil, segundo o $6^{\circ}$ boletim epidemiológico especial do Centro de Operações de Emergências em Saúde Pública da COVID-19, datado do dia 03/04/2020, dos 359 óbitos até então, 286 já possuíam investigação concluída. A maior letalidade encontrada foi no estado do Piauí, com cerca de 18\%. Deste montante, $165(57,7 \%)$ eram do sexo masculino, 242 (85\%) tinham 60 anos ou mais, 30 (10,48\%) tinham entre 40 e 59 anos, $13(4,54 \%)$ tinham entre 20 e 39 anos e apenas $1(0,35 \%)$ tinha de 6 a 19 anos. A maioria dos óbitos investigados $(82 \%)$ apresentava pelo menos um fator de risco, predominando cardiopatias $\quad(57,34 \%)$, diabetes $\quad(39,86 \%)$, pneumopatias $(15,73 \%)$, doenças neurológicas $(10,48 \%)$ e nefropatias $(7,69 \%)$ (Ministério da Saúde, 2020c).

Figura 6. Distribuição por UF das taxas de letalidade da 6 COVID-19 no Brasil.
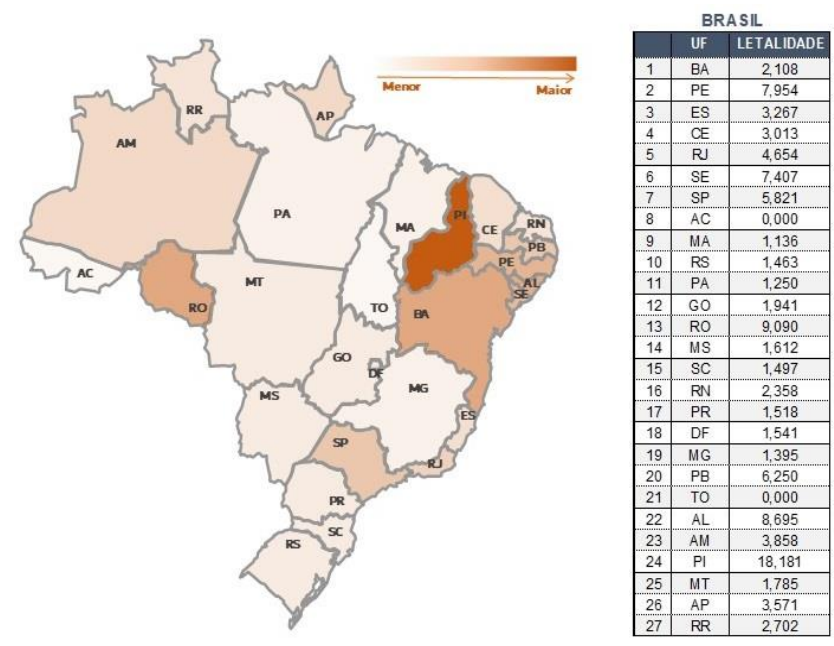

Fonte: Ministério da Saúde. Dados atualizados em 04 de abril de 2020, sujeitos a revisões.

\section{Quadro clínico}

A apresentação clínica da COVID-19 abrange desde um estado assintomático à síndrome do desconforto respiratório agudo e disfunção de múltiplos órgãos. O quadro clínico comum inclui sintomas inespecíficos como febre maior ou igual a 38 ${ }^{\circ} \mathrm{C}$ com calafrios, mialgia generalizada, dor de 
garganta, fadiga, cefaleia e dispneia. A ocorrência de hemoptise também foi descrita, porém como sintoma menos comum. Os sintomas extrapulmonares incluem náuseas, vômitos, diarreia Esses pacientes podem evoluir com pneumonia, insuficiência respiratória e morte. Infecções bacterianas secundárias podem levar à pneumonia bacteriana secundária. (Kannan et al, 2020; Kim, 2020; Lake, 2020; Meo et al, 2020; Singhal, 2020; Peng et al., 2020; Xu et al, 2020; Wujtewicz et al, 2020).

A doença é caracterizada como leve a moderada quando se apresenta como um quadro de síndrome gripal com sintomas leves e ausência de comorbidades descompensadas, sem a necessidade de internação hospitalar ou oxigenoterapia. Esses casos podem ser acompanhados a nível de APS/ESF pela menor gravidade do quadro. Já a doença grave é observada em pacientes que apresentam síndrome gripal com sinais e sintomas de gravidade ou condições clínicas de risco, como hipertensão e diabetes descompensadas, paciente em hemodiálise ou insuficiência hepática, necessitando de estabilização e encaminhamento a centro de referência/urgência. (Ministério da Saúde, 2020b).

São considerados sinais e sintomas de gravidade em adultos o déficit no sistema respiratório, incluindo falta de ar ou dificuldade respiratória, ronco, retração sub/intercostal severa, cianose central, saturação de oximetria de pulso $<95 \%$ em ar ambiente ou taquipneia, > $30 \mathrm{mpm}$. Déficit no sistema cardiovascular também caracteriza gravidade, representado por sinais e sintomas de hipotensão (sistólica > $90 \mathrm{mmHg}$ e/ou diastólica $>60 \mathrm{mmHg}$ ) ou diminuição do pulso periférico. Sinais de alerta adicionais incluem piora nas condições clínicas de doenças de base, alteração do estado mental e persistência ou aumento da febre por mais de 3 dias ou retorno após 48 horas de período afebril. Nas crianças, alguns sinais devem ser observados além dos descritos para adultos, como batimento de asa de nariz, movimento paradoxal do abdome, bradipneia e ritmo respiratório irregular. Os sinais de alerta adicionais são inapetência para amamentação ou ingestão de líquidos, alteração do estado mental, convulsão, confusão e letargia (Ministério da Saúde, 2020b).

As complicações observadas incluíram lesão pulmonar aguda, síndrome do desconforto respiratório agudo, choque, insuficiência renal aguda e disfunção hepática. A ocorrência de resultados adversos, necessidade de ventilação mecânica, tratamento em UTI e morte são mais comuns em idosos, em pacientes com uso de hormônios ou imunossupressores com diminuição da função imunológica e nos que apresentam comorbidades, incluindo hipertensão, diabetes, doença arterial coronariana, DPOC e doença de Parkinson (Singhal, 2020; Wujtewicz et al., 2020). Os dados clínicos e bioquímicos podem ser mascarados por convulsões crônicas coexistentes e 7 leucemia linfocítica (Jin et al., 2020). Atualmente não há evidência de infecção intrauterina por transmissão vertical em gestantes que testaram positivo para a COVID-19 no terceiro trimestre da gestação (Chen et al., 2020).

As principais alterações laboratoriais encontradas nos pacientes foram leucopenia, linfopenia, proteína $\mathrm{C}$ reativa alterada e aspartato aminotransferase (AST) elevada. Pacientes da UTI demonstraram elevação de protrombina, dímero $\mathrm{D}$, e troponina (hs-cTnI) elevada em alguns casos, sugestivo de lesão miocárdica associada ao vírus (Shi et al., 2020; Lake, 2020). Além disso, um estudo com 41 pacientes hospitalizados revelou altos níveis de citocinas pró-inflamatórias, incluindo IL-2, IL-7, IL10, G-CSF, IP-10, MCP-1, MIP-1A e TNF em pacientes graves, achados semelhantes a SARS e MERS. Essa "tempestade de citocinas" pode ser preditiva de agravamento do quadro, tendo como possíveis consequências a sepse viral e a lesão 
pulmonar induzida pelo processo inflamatório, que leva a outras complicações como pneumonia, síndrome do desconforto respiratório agudo, insuficiência respiratória aguda, choque, falência de órgãos e morte (Prompetchara et al., 2020).

No que diz respeito aos achados de imagem, a radiografia de tórax geralmente apresenta infiltrados bilaterais, pode revelar opacidades em vidro fosco, alterações intersticiais e atelectasia. Entretanto, existe a possibilidade de não serem observadas alterações no início da infecção. Já a Tomografia Computadorizada (TC) revela múltiplas regiões de consolidações irregulares e opacidades em vidro fosco com envolvimento bilateral do pulmão. Essas lesões se estendem ao longo dos feixes brônquicos ou nas regiões subpleurais. A distribuição é majoritariamente periférica (Duan e Qin, 2020; SHI et al., 2020; Fan et al., 2020; Fang et al., 2020; Goh et al., 2020; Kin et al, 2020; Lei et al., 2020; Lin et al., 2020; Li et al, 2020; Liu et al, 2020b; Liu e Tan, 2020; Park et al., 2020; Singhal, 2020; Wei, 2020).

O uso da ultrassonografia pulmonar já foi bem descrito na avaliação de condições respiratórias. A primeira descrição do uso de ultrassonografia em paciente positivo para COVID-19 documentou sinais sugestivos de dano intersticial-alveolar, mostrando anormalidades bilaterais difusas da linha pleural, consolidações subpleurais e artefatos verticais espessos e irregulares (Buonsenso et al., 2020).

\section{Diagnóstico}

As definições de caso suspeito e confirmado são importantes no manejo do paciente. De acordo com o Protocolo de Manejo Clínico do Coronavírus (COVID-19) na Atenção Primária à Saúde do Ministério da Saúde, casos suspeitos de síndrome gripal são considerados casos suspeitos de COVID-19 (Ministério da Saúde, 2020b). Um caso suspeito de Síndrome Gripal é definido como um indivíduo com quadro respiratório agudo, com febre ou sensação febril de início súbito, acompanhada de dor de garganta ou tosse ou dificuldade respiratória, na ausência de outro diagnóstico específico. Em crianças, a obstrução nasal também pode se fazer presente. Nos casos dos idosos, é importante ressaltar que há alguns critérios de agravamento específicos como irritabilidade, confusão mental, síncope, sonolência excessiva, irritabilidade e inapetência. A febre pode estar ausente em idosos, crianças e pacientes imunossuprimidos (Tapé et al., 2020; Ministério da Saúde, 2020b; Ministério da Saúde, 2020d; Singhal, 2020; World Health Organization, 2020b). Já um caso suspeito de Síndrome Respiratória Aguda Grave (SRAG) é definido como uma síndrome gripal que apresente pelo menos um dos seguintes sintomas: dispneia/desconforto respiratório, pressão persistente no tórax, saturação de oxigênio menor que $95 \%$, cianose (Ministério da Saúde, 2020d; Singhal, 2020; 8 World Health Organization, 2020b).

Para definir um caso confirmado da COVID19 são analisados os critérios laboratorial e clínicoepidemiológico. O critério laboratorial é definido com um caso suspeito de síndrome gripal ou SRAG com teste de biologia molecular (RT-PCR em tempo real) ou teste imunológico positivos. Já o critério clínicoepidemiológico baseia-se na constatação de um paciente que tem histórico de contato próximo ou domiciliar com caso confirmado laboratorialmente ou caso que não foi possível investigação específica, nos últimos 7 dias antes do aparecimento dos sintomas (Ministério da Saúde, 2020d; World Health Organization, 2020b).

Os casos confirmados por critério laboratorial são diagnosticados por meio de biologia molecular e testes sorológicos específicos para COVID-19. Os testes moleculares são baseados em hibridação por PCR (RT-PCR em tempo real, detecção do vírus SARS-CoV2, influenza ou vírus sincicial respiratório) 
(Kannan et al., 2020; Lake, 2020; Singhal, 2020; Xu et al., 2020; Ministério da Saúde, 2020d; World Health Organization, 2020b). Os testes sorológicos empregam ensaio de imunoabsorção ligado à enzima (ELISA). Já a detecção dos antígenos virais presentes nas amostras é feita por meio do teste de imunofluorescência indireta (IFA). As amostras utilizadas são secreções nasais, sangue, escarro e lavado broncoalveolar (LBA) coletados de casos suspeitos (Kannan, et al, 2020). É importante ressaltar que as características da TC podem auxiliar no diagnóstico, principalmente na ocorrência de resultados falso-negativos nos exames moleculares $(\mathrm{Li}$ et al., 2020).

\section{RT-PCR}

O teste padrão ouro para identificação do novo coronavírus é a RT-PCR em tempo real, sendo o teste de escolha para diagnóstico de pacientes sintomáticos na fase aguda da infecção, realizado entre o $3^{\circ}$ e $7^{\circ}$ dia da doença. Esse teste molecular se baseia no princípio da reação em cadeia da polimerase (PCR), onde o material inicial na reação é o RNA que é transcrito em DNA pela enzima transcriptase reversa. Os genes virais alvos do SARS-CoV-2 são: N, E, S e RdRP. A detecção dos genes é feita em amostra de Swab nasofaríngeo e/ou aspirado/ lavado nasal. Também é feita a homogeneização da amostra, descontaminação e inativação do bacilo, extração, amplificação e detecção do RNA. Dessa forma, impede-se a contaminação cruzada (Singhal, 2020; Xu et al., 2020; Mcmichael,2020; Ministério da Saúde, 2020d; World Health Organization, 2020b).

\section{Testes sorológicos}

Esses testes visam detectar anticorpo específico produzido pelo corpo humano contra o vírus SARS-CoV-2 ou detectar antígeno viral. Para tal, os métodos sorológicos desenvolvidos para detecção de
$\operatorname{IgM}$ e IgG ou detecção de antígenos específicos são feitos por ensaios imunoenzimáticos (ELISA), imunocromatográficos e por imunofluorescência. As amostras utilizadas são de sangue total, soro ou plasma. São testes de triagem e auxílio de diagnóstico. Portanto, os resultados negativos não excluem a infecção por SARS-CoV-2 e o resultado positivo não pode ser usado como evidência absoluta (Kannan, et al., 2020; Ministério da Saúde, 2020d; World Health Organization, 2020b).

\section{Diagnóstico diferencial}

O diagnóstico diferencial inclui as doenças respiratórias clinicamente muito semelhantes à COVID-19, que incluem principalmente aquelas causadas por infecções virais (influenza, parainfluenza, vírus sincicial respiratório, adenovírus, metapneumovirus humano, por exemplo), por infecções bacterianas e por microrganismos atípicos, 9 como micoplasma e clamídia (Singhal, 2020).

\section{Tratamento}

Ainda não há terapias que tenham se mostrado claramente eficazes. Vários tratamentos estão sendo avaliados e embora alguns deles estejam clinicamente disponíveis para outras indicações, seu uso para a COVID-19 permanece em investigação. A abordagem atual ainda é essencialmente de suporte sintomático, devendo-se levar em consideração os demais diagnósticos diferenciais pertinentes (Adhikari et al., 2020; Giwa et al., 2020; Jin et al., 2020; Lake, 2020; Singhal, 2020).

O isolamento domiciliar é considerado no caso de pacientes que apresentam sintomas leves (Jin et al., 2020). Nesse contexto, é necessário garantir o isolamento adequado para impedir a transmissão a outros indivíduos. Estes pacientes devem ter o auxílio de informação profissional e manter sua hidratação, nutrição e controle de seus sinais vitais, além de 
estarem atentos ao possível agravamento dos sintomas (Singhal, 2020).

O suporte respirSinghalrio inclui oxigenoterapia geral, cânula nasal de alto fluxo, ventilação não invasiva e ventilação mecânica invasiva, dependendo da gravidade da doença (Arabi et al., 2020; Lazzeri et al., 2020; LI, 2020; Singhal, 2020; Yi et al., 2020; Zheng, 2020). A OMS recomenda a oxigenação por membrana extracorpórea (ECMO) a pacientes com hipoxemia refratária (Guo et al., 2020).

\section{Plasma convalescente}

Com respaldo nas evidências existentes e na experiência anterior no tratamento de outras infecções virais, como influenza, SARS, MERS e Ebola, foi possível observar que a administração precoce de plasma convalescente ou imunoglobulina hiperimune de pacientes que apresentam títulos significativos de anticorpos pode reduzir a carga viral e a mortalidade da doença. Entretanto, alguns desafios como a disponibilidade de doadores suficientes, a condição clínica, a cinética viral e as interações com o SARSCoV-2 no hospedeiro precisam ser elucidadas antes de considerar-se o plasma convalescente como uma opção terapêutica (Kruse, 2020; Shanmugaraj et al., 2020).

\section{Anticorpos neutralizantes na proteína spike do sars-cov-2}

O uso de anticorpos monoclonais supera muitas desvantagens associadas à terapia com soro e preparações de imunoglobulinas intravenosas no que diz respeito à especificidade, pureza, baixo risco de contaminação e segurança de patógenos transmitidos pelo sangue. Porém, a produção em larga escala de anticorpos monoclonais é trabalhosa, dispendiosa e demorada (Shanmugaraj et al., 2020).
A proteína spike presente na membrana do SARS-CoV-2 desempenha um papel vital na entrada do vírus e é o principal componente antigênico responsável por induzir a resposta imune do hospedeiro. Os anticorpos monoclonais neutralizantes específicos contra o domínio de ligação ao receptor (RBD) na proteína spike ou anticorpo específico que se liga à ACE2 podem efetivamente bloquear a entrada do vírus. Dessa forma, como há alta similaridade entre o domínio RBD do SARS-CoV-2 e SARS-CoV e como ambos usam o mesmo receptor da superfície da célula hospedeira, potenciais agentes ou estratégias de bloqueio testados para impedir a entrada do vírus estão sendo avaliados em relação ao SARS-CoV-2 (Kruse, 2020; Shanmugaraj et al., 2020; Zhou e Zhao, 2020).

\section{Cloroquina/hidroxicloroquina}

A cloroquina é um medicamento conhecido desde 1934 usado no tratamento e prevenção da 10 malária, além de ser utilizado na prática reumatológica como agente imunomodulador (Sarzi-Puttini et al., 2020; Zhang e Liu, 2020). Alguns estudos demonstraram que ela possui atividade antiviral de amplo espectro, particularmente contra a SARS e a influenza A aviária (H5N1). Ela atua aumentando o pH endossômico, fato que interfere na fusão entre as células virais e hospedeiras. Além disso, estudos in vitro mostraram que o processo de glicosilação do receptor ACE2 é afetado, fazendo com que as células Vero pré-tratadas com cloroquina sejam refratárias à infecção por SARS-CoV, fatores que podem inibir a entrada viral nas células-alvo (Agrawal et al., 2020; Sarzi-Puttini et al., 2020; Prajapat et al., 2020; Yang e Shen, 2020).

A hidroxicloroquina tem o mesmo mecanismo de ação, porém um perfil de segurança melhor que a cloroquina, o que torna preferível a sua escolha. Ambas demonstraram ter efeitos imunomoduladores, 
o que pode ter um papel na redução da gravidade da doença por coronavírus (Agrawal et al., 2020).

Um ensaio clínico multicêntrico chinês envolvendo mais de 100 pacientes diagnosticados com COVID-19 mostrou que a ação da cloroquina, comparada ao grupo controle, é superior na redução da duração dos sintomas e exacerbação da pneumonia, promovendo a melhora radiológica sem efeitos colaterais graves. Esse foi o primeiro estudo realizado em humanos para testar a eficácia da cloroquina em pacientes diagnosticados com COVID-19. Entretanto, os resultados detalhados deste estudo ainda não foram publicados e estão disponíveis apenas em forma de carta (Agrawal et al., 2020; Gao et al., 2020).

Um ensaio clínico aberto não randomizado realizado por pesquisadores franceses foi realizado com pacientes hospitalizados com diagnóstico documentado de infecção por COVID-19. Eles incluíram 36 pacientes no estudo e 20 pacientes receberam hidroxicloroquina na dose de $600 \mathrm{mg}$ por dia associada a azitromicina. Após 6 dias de tratamento, $70 \%$ do grupo hidroxicloroquina estava sem detecção viral versus 12,5\% no grupo controle (p $=0.001)$ (Agrawal et al., 2020; Gautret et al., 2020).

Os pacientes que fazem uso desses medicamentos devem ser monitorados com frequência no que diz respeito a parâmetros hematológicos, eletrólitos séricos, glicemia, função hepática e renal. Como esses medicamentos causam prolongamento do intervalo QTc, realizar o ECG antes do início da administração desses fármacos é fundamental. $\mathrm{O}$ uso concomitante de outros medicamentos que causam prolongamento do intervalo QTc deve ser evitado (Agrawal et al., 2020).

\section{Lopinavir-ritonavir}

A combinação de lopinavir com ritonavir, denominada comercialmente de Kaletra ${ }^{\circledR}$, é amplamente utilizada como inibidora da protease no tratamento da infecção pelo HIV (Whang et al., 2020). Essa associação aumenta a meia-vida do lopinavir por meio da inibição do citocromo P450 (Li et al., 2020; Zhang e Liu, 2020). As evidências que documentam a atuação desse fármaco na redução da incidência e mortalidade ocasionada pela Síndrome da Angústia Respiratória do Adulto em pacientes infectados com SARS-CoV-1 e MERS-CoV são limitadas a séries de casos e relatos de casos (iwa

Em um estudo randomizado publicado no New England Journal of Medicine com 199 pacientes com COVID-19 grave, a adição de lopinavir-ritonavir (400 e $100 \mathrm{mg}$, respectivamente) duas vezes ao dia por 14 dias ao tratamento padrão não diminuiu o tempo para melhora clínica em comparação com o tratamento padrão sozinho (Cao et al., 2020; Giwa et al., 2020). Além disso, foi relatado que as cargas virais de $\beta$ coronavírus de um paciente com COVID-19 na Coréia diminuíram significativamente após o tratamento com 11 Kaletra®. O medicamento foi iniciado no oitavo dia de internação (lopinavir $200 \mathrm{mg} /$ ritonavir $50 \mathrm{mg}$ ). É possível que a carga reduzida de SARS-CoV-2 tenha resultado do curso natural do processo de cura da doença, em vez da administração de lopinavir/ritonavir, ou em decorrência de ambos (Lim et al., 2020).

No momento, o uso de antivirais combinados no tratamento da COVID-19 é controverso, pois atualmente não há ensaios clínicos randomizados em humanos para comprovar a eficácia de seu uso (Giwa et al., 2020).

\section{Remdesivir}

O remdesivir foi recentemente reconhecido como uma droga antiviral promissora contra vários vírus de RNA (incluindo o SARS e MERS-CoV) em células cultivadas e nos modelos de camundongo e primatas não humanos (PNH) (Li et al., 2020). Funcionando como um análogo da adenosina 
direcionado ao RdRp, esse fármaco pode desencadear o término prematuro da transcrição do vírus (Zheng, 2020).

No primeiro caso de infecção por SARS-CoV2 nos Estados Unidos, o tratamento com remdesivir foi feito por via intravenosa ao paciente no sétimo dia de internação, sem nenhum evento adverso observado. Observou-se melhora da condição clínica do paciente no oitavo dia e os estertores bilaterais anteriores do lobo inferior desapareceram, fato que demonstra que o remdesivir pode ser eficaz no tratamento da infecção por SARS-CoV-2 (Holshue et al., 2020). No entanto, ensaios clínicos randomizados e controlados ainda são necessários para determinar a segurança e eficácia desse medicamento (Yang et al., 2020; Zhang e Liu, 2020).

\section{Corticosteroides}

O uso de corticosteróides para SDRA grave é controverso. Eles podem suprimir a resposta inflamatória sistêmica exuberante associada à SDRA, mas não há evidências de que eles levem a uma melhora clínica em pacientes com pneumonia intersticial viral (particularmente SARS, MERS e H1N1) e podem até exacerbar a lesão pulmonar (Jin et al., 2020; Sarzi-Puttini et al., 2020).

Por outro lado, os corticosteróides podem modular a liberação de citocinas e suprimir a resposta inflamatória sistêmica exuberante que ocorre na SDRA. A metilprednisolona pode ser usada em pacientes com SDRA em estágio avançado e rápida progressão da doença, pois parece melhorar os sintomas e lesões pulmonares, mas não aumenta a sobrevida global (Sarzi- Puttini et al., 2020).

Um estudo recente realizado na China, examinando fatores de risco associados ao desenvolvimento de SDRA em pacientes com COVID-19, descobriu que o tratamento com metilprednisolona diminuiu o risco de morte entre pacientes com SDRA (hazard ratio, 0.38; IC 95\%, 0,20-0,72). Esses dados apoiam a teoria de que a piora em pacientes com COVID-19 ocorre secundária à imunopatogênese e ao desenvolvimento de uma "tempestade de citocinas", que pode ser mitigada pela administração de glicocorticóides em pacientes com SDRA grave (Giwa et al., 2020).

\section{Vacina}

Com 2 meses do surto de Sars-CoV-2, pelo menos 37 empresas ou grupos de pesquisa de diversos países já estavam se desdobrando para desenvolver uma vacina profilática (Prompetchara et al., 2020). Nos Estados Unidos, um ensaio clínico com a vacina denominada mRNA-1273 está em andamento desde março com uma amostra de 45 voluntários. Na China (Wuhan), também em março, outro estudo começou a ser desenvolvido e encontra-se na Fase I. Nele está sendo testada a vacina recombinante de adenovírus (Ad5-nCoV) com uma amostra 108 adultos saudáveis (Agrawal et al., 2020).

Diversas plataformas estão sendo utilizadas nos testes, tais como mRNA, DNA, vetor adenoviral e proteína recombinante (Chen et al., 2020; Prompetchara et al., 2020). O domínio de ligação ao receptor (RBD) na proteína spike (S), por exemplo, pode ser considerado um bom antígeno da vacina, pois pode induzir anticorpos neutralizantes que impedem a ligação e infecção das células hospedeiras (Prompetchara et al., 2020).

Embora os estudos sejam promissores, a disponibilidade e o uso generalizado da vacina ainda devem demorar pelo menos 18 meses para se estabelecerem (Giwa et al., 2020; Yi et al., 2020).

Entre os desafios para o desenvolvimento bem-sucedido de uma vacina, encontram-se o entendimento incompleto da transmissão viral, da patogênese e da resposta imune (Giwa et al., 2020). São exemplos destes desafios: a falta de modelos 
animais adequados para avaliar a eficácia da vacina; mutações nos epítopos de anticorpos de neutralização da proteína $\mathrm{S}$ e o fato das vacinas de DNA poderem se recombinar com outros vírus (Yu et al., 2020).

Nesse contexto, a coleta de informações relevantes para o desenvolvimento e a avaliação da vacina devem ser bem definidas. Para isso, faz-se necessário encontrar antígenos alvos, ter escalabilidade, instalação de produção, um perfil do produto alvo, previsão de surtos, população alvo, conhecimento das vias de imunização e de modelos animais apropriados (Prompetchara et al., 2020).

\section{CONCLUSÃO}

Dadas as diversas incertezas em relação ao SARS-CoV-2, como a falta de entendimento completo acerca da transmissão viral, da patogênese e da resposta imune, encontra-se ainda muita dificuldade quanto a seu combate. Em larga escala, a primeira resposta contra a doença tem sido a quarentena, adotada em quase todos os países afetados.

No que concerne ao tratamento, ainda não se tem nenhum estudo até a data da revisão em questão que demonstrou total eficácia contra o SARS-CoV-2. Muitos dos trabalhos realizados até então apresentam falhas metodológicas e, nesse contexto, ainda são necessários ensaios clínicos randomizados para trazer informações mais concretas acerca do tema. Outro desafio mundial diz respeito aos casos subnotificados, o que leva a uma necessidade de expansão dos testes.

Ressalta-se que nesse momento de pandemia as informações mudam constantemente e alguns conteúdos desta revisão podem alterar-se nos próximos dias ou meses.

\section{AGRADECIMENTO}

Ao Dr. Benito Rolando Gutiérrez Martinez pela tradução e revisão do resumo para o espanhol.
Todos os autores declararam não haver qualquer potencial conflito de interesses referente a este artigo.

\section{REFERÊNCIAS}

ADHIKARI, S.P.; MENG, S.; WU, Y.J.; MAO, Y.P.; YE, R.X.; WANG, Q.Z.; SUN, C.; SYLVIA, S.; ROZELLE, S; RAAT, H.; ZHOU, H. Epidemiology, causes, clinical manifestation and diagnosis, prevention and control of coronavirus disease (COVID-19) during the early outbreak period: a scoping review. Infectious diseases of poverty, v. 9, n. 1, p. 1-12, 2020.

AGRAWAL, S.; GOEL, A.D.; GUPTA, N. Emerging prophylaxis strategies against COVID-19. Monaldi Archives for Chest Disease, v. 90, n. 1, 2020.

ARABI, Y.M.; FOWLER, R.; HAYDEN, F.G. Critical care management of adults with communityacquired severe respiratory viral infection. Intensive care medicine, v. 46, n. 2, p. 315-328, 2020.

BUONSENSO, D.; PIANO, A.; RAFFAELLI, F.; BONADIA, D.; DONATI, K.D.G.; FRANCESCHI, F. Point-of-Care Lung Ultrasound findings in novel 13 coronavirus disease-19 pneumoniae: a case report and potential applications during COVID-19 outbreak European review for medical and pharmacological sciences, v. 24, p. 2776-2780, 2020

CAO, B.; WANG, Y.; WEN, D.; LIU, W.; WANG, J; FAN, G.; RUAN, L.; SONG, B.; CAI, Y.; WEI, M.; LI, X.; XIA, J.; CHEN, N.; XIANG, J.; YU, T.; BAI, T.; XIE, X.; ZHANG, L.; LI, C.; YUAN, Y.; CHEN, H.; LI, H.; HUANG, H.; TU, S.; GONG, F.; LIU, Y.; WEI, Y.; DONG, C.; ZHOU, F.; GU, X.; XU, J.; LIU, Z.; ZHANG, Y.; LI, H.; SHANG, L.; WANG, K.; LI, K.; ZHOU, X.; DONG, X.; QU, Z.; LU, S.; HU, X.; RUAN, S.; LUO, S.; WU, J.; LU, P.; CHENG, F.; PAN, L.; ZOU, J.; JIA, C.; WANG, J.; LIU, X.; WANG, S.; WU, X.; GE, Q.; HE, J.; ZHAN, H.; QIU, F.; GUO, L.; HUANG, C.; JAKI, T.; HAYDEN, F.G.; HORBY, P.W.; ZHANG, D.; WANG, C. A trial of lopinavir-ritonavir in adults hospitalized with severe Covid-19. New England journal of medicine, v. 382, p. 1787-1799, 2020.

CHEN, H.; GUO, J.; WANG, C.; LUO, F.; YU, X.; ZHANG, W.; LI, J.; ZHAO, D.; XU, D.; GONG, Q.; LIAO, J.; YANG, H.; HOU, W.; ZHANG, Y. Clinical characteristics and intrauterine vertical transmission potential of COVID-19 infection in nine pregnant women: a retrospective review of medical records. The Lancet, v. 395, n. 10226, p. 809-815, 2020. 
CHEN, Y.; LIU, Q.; GUO, D. Emerging coronaviruses: genome structure, replication, and pathogenesis. Journal of medical virology, v. 92, n. 4, p. 418-423, 2020.

CHENG, S.C.; CHANG, Y.C.; CHIANG, Y.L.F; CHIEN, Y.C; CHENG, M.; YANG, C.H.; HUANG, C.H.; HSU, Y.N. First case of Coronavirus Disease 2019 (COVID-19) pneumonia in Taiwan. Journal of the Formosan Medical Association, 2020.

CHENG, Z.J. e Shan, J. 2019 Novel coronavirus: where we are and what we know. Infection, v.48, n. 2, p. $155-63,2020$.

DUAN, Y.N. e QIN, J. Pre-and posttreatment chest CT findings: 2019 novel coronavirus $(2019-\mathrm{nCoV})$ pneumonia. Radiology, v. 295, n. 1, p. 21-21, 2020.

FANG, Y.; ZHANG, H.; XU, Y.; XIE, J.; PANG, P.; JI, W.1. CT manifestations of two cases of 2019 novel coronavirus (2019-nCoV) pneumonia. Radiology, v. 295, n. 1, p. 208-209, 2020.

FUNG, S.Y.; YUEN, K.S.; YE, Z.W.; CHAN, C.P.; JIN, D.Y. A tug-of-war between severe acute respiratory syndrome coronavirus 2 and host antiviral defence: lessons from other pathogenic viruses. Emerging microbes \& infections, v. 9, n. 1, p. 558570, 2020.

GAO, J.; TIAN, Z.; Yang, X. breakthrough: chloroquine phosphate has shown apparent efficacy in treatment of covId-19 associated pneumonia in clinical studies. biosci Trends. 2020 epub ahead of print. Press. doi, v. 10.

GAUTRET, P.; LAGIER， J.C.; PAROLA， P.; HOANG, V.T.; MEDDEB, L.; MAILHE, M.; DOUDIER, B.; COURJON, J.; GIORDANENGO, V.; VIEIRA, V.E.; DUPONT, H.T.; HONORÉ, S.; COLSON, P.; CHABRIERE, E.; LA SCOLA, B.; ROLAIN, J.M.; BROUQUI, P.; RAOULT, D. Hydroxychloroquine and Azithromycin as a treatment of COVID-19: preliminary results of an open-label non-randomized clinical trial International journal of antimicrobial agents, p. 105949, 2020.

GIWA, A.L.; DESAI, A.; DUCA, A. Novel 2019 coronavirus SARS-CoV-2 (COVID-19): an overview for emergency clinicians. Pediatric Emergency Medicine Practice, v. 17, n. 5, p. 1-24, 2020.

GOH, K.J.; CHOONG, M.C.; CHEONG, E.H.; KALIMUDDIN, S.; WEN, S.D.; PHUA, G.C.; CHAN, K.S.; MOHIDEEN, S.H. Rapid progression to acute respiratory distress syndrome: review of current understanding of critical illness from COVID-19
Infection. Ann Acad Med Singapore, v. 49, n. 1, p. 19, 2020.

GUAN, W.J.; NI, Z.Y; HU, Y.; LIANG, W.H.; OU, C.Q.; HE, J.X.; LIU, L.; SHAN, H.; LEI, C.L.; HUI, D.S.C.; DU, B.; LI, L.J.; ZENG, G.; YUEN, K.Y.; CHEN, R.C.; TANG, C.L.; WANG, T.; CHEN, P.Y.; XIANG, J.; LI, S.Y.; WANG, J.L.; LIANG, Z.J.; PENG, Y.X.; WEI, L.; LIU, Y.; HU, Y.H.; PENG, P.; WANG, J.M.; LIU, J.Y.; CHEN, Z.; LI, G.; ZHENG, Z.J.; QIU, S.Q.; LUO, J.; YE, C.J.; ZHU, S.Y.; ZHONG, N.S.. Clinical characteristics of coronavirus disease 2019 in China. New England journal of medicine, v. 382, n. 18, p. 1708-1720, 2020.

GUO, Y.R.; CAO, Q.D.; HONG, Z.S.; TAN, Y.Y.; CHEN, S.D.; JIN, H.J.; TAN, K.S.; WANG, D..Y; YAN, Y. The origin, transmission and clinical therapies on coronavirus disease 2019 (COVID-19) outbreak-an update on the status. Military Medical Research, v. 7, n. 1, p. 1-10, 2020.

IBGE. Projeção da população do Brasil e das Unidades da Federação. In: Instituto Brasileiro de Geografia e Estatística. Rio de Janeiro, 2020. Disponível em: https://www.ibge.gov.br/apps/populacao/projecao/.

Acesso em: 13 abr. 2020.

JIN, X.H.; ZHENG, K.I.; PAN, K.H.; XIE, Y.P.; ZHENG, M.H. COVID-19 in a patient with chronic lymphocytic leukaemia. The Lancet Haematology, v. 7, n. 4, p. e351-e352, 2020.

JIN, Y.; YANG, H.; JI, W.; WU, W.; CHEN, S.; ZHANG, W.; DUAN, G. Virology, epidemiology, pathogenesis, and control of COVID-19. Viruses, v. 12 , n. 4, p. 372, 2020.

JIN, Y.H.; CAI, L.; CHENG, Z.S.; CHENG, H.; DENG, T.; FAN, Y.P.; FANG, C.; HUANG, D.; HUANG, L.Q.; HUANG, Q.; HAN, Y.; HU, B.; HU, F.; LI, B.H.; LI, Y.R.; LIANG, K.; LIN, L.K.; LUO, L.S.; MA, J.; MA, L.L.; PENG, Z.Y.; PAN, Y.B.; PAN, Z.Y.; REN, X.Q.; SUN, H.M.; WANG, Y.; WANG, Y.Y.; WENG, H.; WEI, C.J.; WU, D.F.; XIA, J.; XIONG, Y; XU, H.B; YAO, X.M.; YUAN, Y.F.; YE, T.S.; ZHANG, X.C.; ZHANG, Y.W.; ZHANG, Y.G.; ZHANG, H.M.; ZHAO, Y.; ZHAO, M.L.; ZI, H;. ZHENG, X.T.; WANG, Y.Y; WANG, X.H. A rapid advice guideline for the diagnosis and treatment of 2019 novel coronavirus (2019-nCoV) infected pneumonia (standard version). Military Medical Research, v. 7, n. 1, p. 4, 2020.

KAMPF, G.; TODT, D.; PFAENDER, S.; STEINMANN, E. Persistence of coronaviruses on inanimate surfaces and its inactivation with biocidal agents. Journal of Hospital Infection, 2020. 
KANNAN, S.; ALI, P.S.S.; SHEEZA, A.; HEMALATHA, K. COVID-19 (Novel Coronavirus 2019)-recent trends. European review for medical and pharmacological sciences, v. 24 , n. 4, p. 20062011, 2020.

KIM, J.Y.; CHOE, P.G.; OH, Y.; OH, K.J.; KIM, J.; PARK, S.J.; PARK, J.H; NA, H.K.; OH, M. The first case of 2019 novel coronavirus pneumonia imported into Korea from Wuhan, China: implication for infection prevention and control measures. Journal of Korean medical science, v. 35, n. 5, 2020a.

KIM, J.Y.; KO, J.H; KIM, Y.; KIM, Y.J.; KIM, J.M.; CHUNG, Y.S.; KIM, H.M.; HAN, M.G.; KIM, S.Y.; CHIN, B.S. Viral load kinetics of SARS-CoV-2 infection in first two patients in Korea. Journal of Korean medical science, v. 35, n. 7, 2020.

KRUSE, R.L. Therapeutic strategies in an outbreak scenario to treat the novel coronavirus originating in Wuhan, China. F1000Research, v. 9, 2020.

LAKE, M.A. What we know so far: COVID-19 current clinical knowledge and research. Clinical Medicine, v. 20, n. 2, p. 124, 2020.

LAZZERI, M.; LANZA, A.; BELLINI, R.; BELLOFIORE, A.; CECCHETTO, S.; COLOMBO, A.; D'ABROSCA, F.; MONACO, C.D.; GAUDIELLO, G.; PANERONI, M.; PRIVITERA, E.; RETUCCI, M.; ROSSI, V.; SANTAMBROGIO, M.; SOMMARIVA, M.; FRIGERIO, P. Respiratory physiotherapy in patients with COVID-19 infection in acute setting: a Position Paper of the Italian Association of Respiratory Physiotherapists (ARIR). Monaldi Archives for Chest Disease, v. 90, n. 1, 2020.

LEI, J.; LI, J.; QI, X. CT imaging of the 2019 novel coronavirus (2019-nCoV) pneumonia. Radiology, v. 295, n. 1, p. 18-18, 2020.

LI, D.; WANG, D.; DONG, J.; WANG, N.; HUANG, H.; XU, H.; XIA, C. False-negative results of real-time reverse-transcriptase polymerase chain reaction for severe acute respiratory syndrome coronavirus 2 : role of deep-learning-based CT diagnosis and insights from two cases. Korean journal of radiology, v. 21, n. 4, p. 505-508, 2020.

LI, G.; FAN, Y.; LAI, Y.; HAN, T.; LI, Z.; ZHOU, P.; PAN, P.; WANG, W.; HU, D.; LIU, X.; ZHANG, Q.; WU, J. Coronavirus infections and immune responses. Journal of medical virology, v. 92, n. 4, p. 424-432, 2020.

LI, J.Y.; YOU, Z.; WANG, Q.; ZHOU, Z.J.; QIU, Y.; LUO, R.; GE, X.Y. The epidemic of 2019-novel- coronavirus (2019-nCoV) pneumonia and insights for emerging infectious diseases in the future. Microbes and infection, v. 22, n. 2, p. 80-85, 2020.

LI, T. Diagnosis and clinical management of severe acute respiratory syndrome Coronavirus 2 (SARSCoV-2) infection: an operational recommendation of Peking Union Medical College Hospital (V2. 0) Working Group of 2019 Novel Coronavirus, Peking Union Medical College Hospital. Emerging microbes \& infections, v. 9, n. 1, p. 582-585, 2020.

LIM, J.; JEON, S.; SHIN, H.Y.; KIM, M.J.; SEONG, Y.M.; LEE, W.J.; CHOE, K.W.; KANG, Y.M.; LEE, B.; PARK, S.J. Case of the index patient who caused tertiary transmission of COVID-19 infection in Korea: the application of lopinavir/ritonavir for the treatment of COVID-19 infected pneumonia monitored by quantitative RT-PCR. Journal of Korean medical science, v. 35, n. 6, 2020.

LIN, X.; GONG, Z.; XIAO, Z.; XIONG, J.; FAN, B.; LIU, J. Novel coronavirus pneumonia outbreak in 2019: computed tomographic findings in two cases. Korean journal of radiology, v. 21, n. 3, p. 365-368, 2020.

LIU, P e TAN, X.Z. 2019 novel coronavirus (2019- 15 nCoV) pneumonia. Radiology, v. 295, n. 1, p. 19-19, 2020.

LIU, Y.; GAYLE, A.A; WILDER-SMITH, A.; ROCKLÖV, J. The reproductive number of COVID19 is higher compared to SARS coronavirus. Journal of travel medicine, 2020a.

LIU, Y.C.; LIAO, C.H.; CHANG, C.F.; CHOU, C.C.; LIN, Y.R. A locally transmitted case of SARS-CoV-2 infection in Taiwan. New England Journal of Medicine, v. 382, n. 11, p. 1070-1072, 2020 b.

MCMICHAEL, T.M. COVID-19 in a long-term care facility-King County, Washington, February 27March 9, 2020. MMWR. Morbidity and Mortality Weekly Report, v. 69, 2020.

MEO, S.A.; ALHOWIKAN, A.M.; AL-KHLAIWI, T.; MEO, I.M.; HALEPOTO, D.M.; IQBAL, M.; USMANI, A.M.; HAJJAR, W.; AHMED, N. Novel coronavirus 2019-nCoV: prevalence, biological and clinical characteristics comparison with SARS-CoV and MERS-CoV. Eur Rev Med Pharmacol Sci, v. 24, n. 4, p. 2012-2019, 2020.

MINISTÉRIO DA SAÚDE (Brasil). Painel de casos de doença pelo coronavírus 2020 (COVID-19) no Brasil pelo Ministério da Saúde. In: Coronavírus Brasil. Brasília, 2020. Disponível em: https://covid.saude.gov.br/. Acesso em: 9 abr. 2020a. 
MINISTÉRIO DA SAÚDE (Brasil). Secretaria de Atenção Primária à Saúde (SAPS). Protocolo de manejo clínico do coronavírus (COVID-19) na atenção primária à saúde. Coronavírus COVID-19, Brasília, p. 1-33, março 2020b.

MINISTÉRIO DA SAÚDE (Brasil). Secretaria de Vigilância em Saúde. Doença pelo Coronavírus 2019. Boletim Epidemiológico Especial 06 - COE Coronavírus, Brasília, 3 abr. 2020. Disponível em: https://portalarquivos.saude.gov.br/images/pdf/2020/ April/03/BE6-Boletim-Especial-do-COE.pdf. Acesso em: 9 abr. 2020c.

MINISTÉRIO DA SAÚDE (Brasil). Secretaria de Vigilância em Saúde. Emergência de Saúde Pública de Importância Nacional pela Doença pelo Coronavírus 2019: Vigilância Integrada de Síndromes Respiratórias Agudas Doença pelo Coronavírus 2019, Influenza e outros vírus respiratórios. Guia de Vigilância Epidemiológica, [s. l.], p. 1-37, 3 abr. $2020 d$.

PARK, J.Y.; HAN, M.S.; PARK, K.U.; KIM, J.Y.; CHOI, E.H. First pediatric case of coronavirus disease 2019 in Korea. Journal of Korean medical science, v. 35, n. 11, 2020.

PARK, W.B.; KWON, N.J.; CHOI, S.J.; KANG, C.K.; CHOE, P.G.; KIM, J.Y.; YUN, J.; LEE, G.W.; SEONG, M.W.; KIM, N.J.; SEO, J.S.; OH, M.D. Virus isolation from the first patient with SARS-CoV2 in Korea. Journal of Korean Medical Science, v. 35, n. 7, 2019.

PENG, X.; XU, X.; LI, Y.; CHENG, L.; ZHOU, X.; REN, B. Transmission routes of 2019-nCoV and controls in dental practice. International Journal of Oral Science, v. 12, n. 1, p. 1-6, 2020.

PHAN, L.T.; NGUYEN, T.V.; LUONG, Q.C.; NGUYEN, T.V.; NGUYEN, H.T.; LE, H.Q.; NGUYEN, T.T.; CAO, T.M.; PHAM, Q.D. Importation and human-to-human transmission of a novel coronavirus in Vietnam. New England Journal of Medicine, v. 382, n. 9, p. 872-874, 2020.

PRAJAPAT, M.; SARMA, P.; SHEKHAR, N.; AVTI, P.; SINHA, S.; KAUR, H.; KUMAR, S.; BHATTACHARYYA, A.; KUMAR, H.; BANSAL, S.; MEDHI, B. Drug targets for corona virus: A systematic review. Indian journal of pharmacology, v. 52, n. 1, p. 56, 2020.

PROMPETCHARA, E.; KETLOY, C.; PALAGA, T. Immune responses in COVID-19 and potential vaccines: Lessons learned from SARS and MERS epidemic. Asian Pac J Allergy Immunol, v. 38, n. 1, p. 1-9, 2020.
QIN, C.; LIU, F.; YEN, T.C; LAN, X. 18 F-FDG PET/CT findings of COVID-19: a series of four highly suspected cases. European Journal of Nuclear Medicine and Molecular Imaging, p. 1-6, 2020.

ROTHE, C.; SCHUNK, M.; SOTHMANN, P.; BRETZEL, G.; FROESCHL, G.; WALLRAUCH, C.; ZIMMER, T.; THIEL, V.; JANKE, C. Transmission of 2019-nCoV infection from an asymptomatic contact in Germany. New England Journal of Medicine, v. 382, n. 10, p. 970-971, 2020.

RYU, S. e CHUN, B.C. An interim review of the epidemiological characteristics of 2019 novel coronavirus. Epidemiology and health, v. 42, 2020.

SARZI-PUTTINI, P.; GIORGI, V.; SIROTTI, S.; MAROTTO, D.; ARDIZZONE, S.; RIZZARDINI, G.; ANTINORI, S.; GALLI, M.; COVID-19, cytokines and immunosuppression: what can we learn from severe acute respiratory syndrome?. Clinical and experimental rheumatology, v. 38, n. 2, p. 337-342, 2020.

SHANMUGARAJ, B.; SIRIWATTANANON, K.; WANGKANONT, K.; PHOOLCHAROEN, W. Perspectives on monoclonal antibody therapy as potential therapeutic intervention for Coronavirus disease-19 (COVID-19). Asian Pac J Allergy Immunol, v. 38, n. 1, p. 10-18, 2020.

SHI, H.; HAN, X.; ZHENG, C. Evolution of CT manifestations in a patient recovered from 2019 novel coronavirus (2019-nCoV) pneumonia in Wuhan, China. Radiology, v. 295, n. 1, p. 20-20, 2020.

SINGHAL, T. A review of coronavirus disease-2019 (COVID-19). The Indian Journal of Pediatrics, p. 16, 2020.

STOECKLIN, S.B; ROLLAND, P.; SILUE, Y.; MAILLES, A.; CAMPESE, C.; SIMONDON, A.; MECHAIN, M.; MEURICE, L.; NGUYEN, M.; BASSI, C.; YAMANI, E.; BEHILLIL, S.; ISMAEL, S.; NGUYEN, D.; MALVY, D.; LESCURE, F.X.; GEORGES, S.; LAZARUS, C.; TABAI, A; STEMPFELET, M.; ENOUF, V; COIGNARD, B. First cases of coronavirus disease 2019 (COVID-19) in France: surveillance, investigations and control measures, January 2020. Eurosurveillance, v. 25, n. 6, p. 2000094, 2020.

SUN, Z.; THILAKAVATHY, K.; KUMAR, S.S.; HE, G.; LIU, S.V. Potential factors influencing repeated SARS outbreaks in China. International Journal of Environmental Research and Public Health, v. 17, n. 5 , p. $1633,2020$. 
TAPÉ, C.; BYRD, K.M.; AUNG, S.; LONKS, J.R.; FLANIGAN, T.P.; RYBAK, N.R. COVID-19 in a Patient Presenting with Syncope and a Normal Chest X-ray. Rhode Island Medical Journal, v. 103, n. 3, p. 50-51, 2020.

WANG, Z.; CHEN, X.; LU, Y.; CHEN, F.; ZHANG, W. Clinical characteristics and therapeutic procedure for four cases with 2019 novel coronavirus pneumonia receiving combined Chinese and Western medicine treatment. Bioscience trends, v. 14, n. 1, p. 64-68, 2020.

WEI, J.; XU, H.; XIONG, J.; SHWN, Q.; FAN, B.; YE, C.; DONG, W.; HU, F. 2019 novel coronavirus (COVID-19) pneumonia: serial computed tomography findings. Korean Journal of Radiology, v. 21, n. 4, p. 501-504, 2020.

WORLD HEALTH ORGANIZATION. Coronavirus disease 2019 (COVID-19): Situation Report - 75. Coronavirus disease (COVID-2019) situation reports. Suíça, 4 abr. 2020. Disponível em: https://www.who.int/docs/defaultsource/coronaviruse/situation-reports/20200404sitrep-75-covid-19.pdf?sfvrsn=99251b2b_4. Acesso em: 9 abr. 2020a.

WORLD HEALTH ORGANIZATION. Orientações provisórias 20 de Março de 2020. Vigilância mundial da COVID-19 causada por infecção humana pelo vírus COVID-19, [S. l.], p. 1-4, 20 mar. 2020. Disponível em:

https://apps.who.int/iris/bitstream/handle/10665/3312 31/WHO-2019-nCoV-SurveillanceGuidance-2020.4por.pdf?sequence $=33 \&$ isAllowed $=y$. Acesso em: 11 maio $2020 \mathrm{~b}$.

WU, F.; ZHAO, S.; YU, B.; CHEN, Y.M; WANG, W.; SONG, Z.G.; HU, Y.; TAO, Z.W; TIAN, J.H.; PEI, Y.Y.; YUAN, M.L.; ZHANG, Y.L; DAI, F.H.; LIU, Y.; WANG, Q.M; ZHENG, J.J.; XU, L.; HOLMES, E.C.; ZHANG, Y.Z. A new coronavirus associated with human respiratory disease in China. Nature, v. 579, n. 7798, p. 265-269, 2020.

WUJTEWICZ, M.; SOMMER, A.D.; ASZKIELOWICZ, A.; ZDANOWSKI, S.; PIWOWARCZYK, S.; OWCZUK, R. COVID-19what should anaethesiologists and intensivists know about it?. Anaesthesiology intensive therapy, v. 52, n. 1, p. 34-41, 2020.

XU, J.; ZHAO, S.; TENG, T.; ABDALLA, A.E; ZHU, W.; XIE, L.; WANG, Y.; GUO, X. Systematic comparison of two animal-to-human transmitted human coronaviruses: SARS-CoV-2 and SARS-CoV. Viruses, v. 12, n. 2, p. 244, 2020.

YANG, N. e SHEN, H.M. Targeting the endocytic pathway and autophagy process as a novel therapeutic strategy in covid-19. International journal of biological sciences, v. 16, n. 10, p. 1724, 2020.

YANG, Y.; ISLAM, M.S.; WANG, J.; LI, Y.; CHEN, $X$. Traditional Chinese medicine in the treatment of patients infected with 2019-new coronavirus (SARSCoV-2): a review and perspective. International journal of biological sciences, v. 16, n. 10, p. 1708, 2020 .

YE, Z.W.; YUAN, S.; YUEN, K.S.; FUNG, S.Y.; CHAN, C.P; JIN, D.Y. Zoonotic origins of human coronaviruses. International journal of biological sciences, v. 16, n. 10, p. 1686, 2020.

YI, Y.; LANIGTON, P.N.P; YE, S.; LI, E.; XU, R.H. COVID-19: what has been learned and to be learned about the novel coronavirus disease. International journal of biological sciences, v. 16, n. 10, p. 1753, 2020 .

YU, F.; DU, L.; OJCIUS, D.M.; PAN, C.; JIANG, S. Measures for diagnosing and treating infections by a novel coronavirus responsible for a pneumonia outbreak originating in Wuhan, China. Microbes and infection, 2020.

ZHANG, L. e LIU, Y. Potential interventions for novel coronavirus in China: a systemic review. Journal of medical virology, 2020.

ZHANG, N.; WANG, L.; DENG, X.; LIANG, R.; SU, M.; CHEN, H.; HU, L.; SU, Y.; REN, J.; YU, F.; DU, L.; JIANG, S.; Recent advances in the detection of respiratory virus infection in humans. Journal medical virology, 2020.

ZHENG, J. SARS-CoV-2: an emerging coronavirus that causes a global threat. International journal of biological sciences, v. 16, n. 10, p. 1678, 2020.

ZHOU, G. e ZHAO, Q. Perspectives on therapeutic neutralizing antibodies against the Novel Coronavirus SARS-CoV-2. International Journal of Biological Sciences, v. 16, n. 10, p. 1718, 2020. 